University of Nebraska - Lincoln

DigitalCommons@University of Nebraska - Lincoln

USDA National Wildlife Research Center - Staff Publications
U.S. Department of Agriculture: Animal and Plant Health Inspection Service

2009

\title{
Assessing Allowable Take of Migratory Birds
}

\author{
Michael Runge \\ United States Geological Survey, Patuxent Wildlife Research Center \\ John Sauer \\ United States Geological Survey, Patuxent Wildlife Research Center \\ Michael L. Avery \\ USDA/APHIS/WS National Wildlife Research Center, michael.I.avery@aphis.usda.gov \\ Bradley F. Blackwell \\ USDA/APHIS/WS National Wildlife Research Center, bradley.f.blackwell@aphis.usda.gov \\ Mark Koneff \\ United States Fish and Wildlife Service, Division of Migratory Bird Management
}

Follow this and additional works at: https://digitalcommons.unl.edu/icwdm_usdanwrc

Part of the Environmental Sciences Commons

Runge, Michael; Sauer, John; Avery, Michael L.; Blackwell, Bradley F.; and Koneff, Mark, "Assessing Allowable Take of Migratory Birds" (2009). USDA National Wildlife Research Center - Staff Publications. 870.

https://digitalcommons.unl.edu/icwdm_usdanwrc/870

This Article is brought to you for free and open access by the U.S. Department of Agriculture: Animal and Plant Health Inspection Service at DigitalCommons@University of Nebraska - Lincoln. It has been accepted for inclusion in USDA National Wildlife Research Center - Staff Publications by an authorized administrator of DigitalCommons@University of Nebraska - Lincoln. 


\title{
Assessing Allowable Take of Migratory Birds
}

\author{
MICHAEL C. RUNGE, ${ }^{1}$ United States Geological Survey, Patuxent Wildlife Research Center, 12100 Beech Forest Road, Laurel, MD 20708, USA \\ JOHN R. SAUER, United States Geological Survey, Patuxent Wildlife Research Center, 12100 Beech Forest Road, Laurel, MD 20708, USA \\ MICHAEL L. AVERY, United States Department of Agriculture, Animal and Plant Health Inspection Service, Wildlife Services, National Wildlife \\ Research Center, Florida Field Station, 2820 E University Avenue, Gainesville, FL 32641, USA \\ BRADLEY F. BLACKWELL, United States Department of Agriculture, Animal and Plant Health Inspection Service, Wildlife Services, National Wildife \\ Research Center, Obio Field Station, 6100 Columbus Avenue, Sandusky, OH 44870, USA \\ MARK D. KONEFF, United States Fish and Wildlife Service, Division of Migratory Bird Management, 11510 American Holly Drive, Laurel, MD
} 20708, USA

\begin{abstract}
Legal removal of migratory birds from the wild occurs for several reasons, including subsistence, sport harvest, damage control, and the pet trade. We argue that harvest theory provides the basis for assessing the impact of authorized take, advance a simplified rendering of harvest theory known as potential biological removal as a useful starting point for assessing take, and demonstrate this approach with a case study of depredation control of black vultures (Coragyps atratus) in Virginia, USA. Based on data from the North American Breeding Bird Survey and other sources, we estimated that the black vulture population in Virginia was 91,190 (95\% credible interval = $44,520-212,100)$ in 2006. Using a simple population model and available estimates of life-history parameters, we estimated the intrinsic rate of growth $\left(r_{\max }\right)$ to be in the range $7-14 \%$, with $10.6 \%$ a plausible point estimate. For a take program to seek an equilibrium population size on the conservative side of the yield curve, the rate of take needs to be less than that which achieves a maximum sustained yield $\left(0.5 \times r_{\text {max }}\right)$. Based on the point estimate for $r_{\max }$ and using the lower $60 \%$ credible interval for population size to account for uncertainty, these conditions would be met if the take of black vultures in Virginia in 2006 was $<3,533$ birds. Based on regular monitoring data, allowable harvest should be adjusted annually to reflect changes in population size. To initiate discussion about how this assessment framework could be related to the laws and regulations that govern authorization of such take, we suggest that the Migratory Bird Treaty Act requires only that take of native migratory birds be sustainable in the long-term, that is, sustained harvest rate should be $<r_{\max }$. Further, the ratio of desired harvest rate to $0.5 \times$ $r_{\max }$ may be a useful metric for ascertaining the applicability of specific requirements of the National Environmental Protection Act. (JOURNAL OF WILDLIFE MANAGEMENT 73(4):556-565; 2009)
\end{abstract}

DOI: $10.2193 / 2008-090$

KEY WORDS adaptive management, allowable take, black vulture, Coragyps atratus, depredation, harvest theory, migratory birds, potential biological removal, prescribed take level, yield curve.

Legal removal of migratory birds from the wild occurs for several reasons, including subsistence, sport harvest, damage control, and the pet trade. In the United States, such take is prohibited under the Migratory Bird Treaty Act (MBTA, 16 USC \$\$703-712), except as allowed by the Secretary of Interior "having due regard ... to the distribution, abundance, economic value, breeding habits, and times and lines of migratory flight of such birds" (16 USC \$704). The MBTA is a central component of the North American model of wildlife conservation, an unparalleled system of sustainable natural resource management (Geist et al. 2001). One of the challenges faced by regulatory agencies such as the United States Fish and Wildlife Service (USFWS) is to determine whether any proposed take is compatible with the intent of the MBTA and other related laws.

Lethal control of wildlife to reduce human-wildlife conflicts is an important, and often contentious, form of take. Overabundant wildlife populations can cause substantial damage to human structures, agricultural crops, and livestock and can create human health and safety hazards. Management of such conflicts, however, has to be tempered by the desire to conserve wild populations of native species, as expressed in various laws like the MBTA. In recent decades, wildlife-damage management agencies have made great strides in developing nonlethal methods to reduce

${ }^{1}$ E-mail: mrunge@usgs.gov many conflicts, but it is clear that lethal control is needed in some circumstances. Increasing human-wildlife conflicts and increasing attention to the methods used to resolve them has created a heightened need for quantitative assessment of the impact of control activities on wildlife populations and a formal framework for determining the level of take that is allowable.

Black vultures (Coragyps atratus) have grown in population throughout the United States in the last 3 decades and have expanded in range in the eastern United States since the 1940s (Greider and Wagner 1960, Buckley 1999, Avery 2004). In the last 15 years, damage by black vultures has increased, particularly in Virginia, where damage to real and personal property as well as depredation of livestock and pets have generated substantial conflicts (Lowney 1999). Nonlethal methods to resolve vulture conflicts include dispersal using pyrotechnics, lasers, and effigies (Avery et al. 2002, Tillman et al. 2002); translocation (Humphrey et al. 2000); and modification of landowner practices to minimize damage (United States Department of Agriculture 2002). When nonlethal methods are ineffective, however, an integrated damage-management program that includes lethal control is required.

We propose a framework, grounded in harvest theory and decision analysis, for assessing and setting allowable levels of take. This framework is flexible enough to allow decisionmakers to balance competing desires to reduce human- 


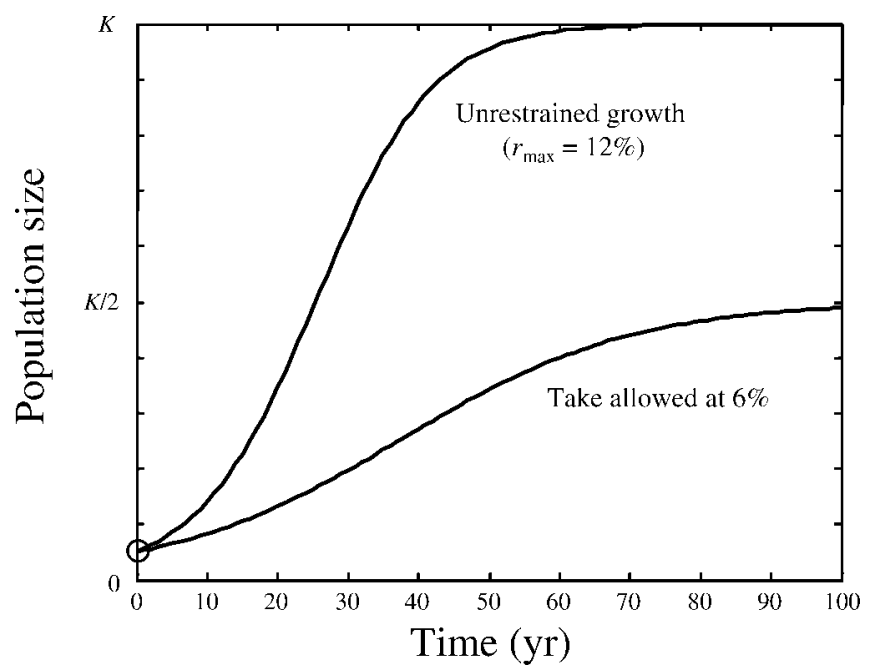

Figure 1. Logistic growth of a population over time, either unconstrained by take (intrinsic growth rate, $r_{\max }=12 \%$ ) or in the presence of take (at $6 \% / y r)$. Note that take decreases the initial rate of growth at low density and lowers the long-term equilibrium to some fraction of carrying capacity $(K)$.

vulture conflicts and to conserve wild vulture populations. We demonstrate use of this framework using black vultures in Virginia.

\section{Harvest Theory as a Framework for Allowable Take}

The fundamentals of harvest theory emerge from consideration of the simplest model for a population subjected to take, the discrete logistic model

$$
N_{t+1}=N_{t}+r_{\max } N_{t}\left(1-N_{t} / K\right)-h_{t} N_{t}
$$

where $N_{t}$ is population size at time $t, r_{\max }$ is maximum growth rate, $K$ is carrying capacity, and $h_{t}$ is harvest rate over

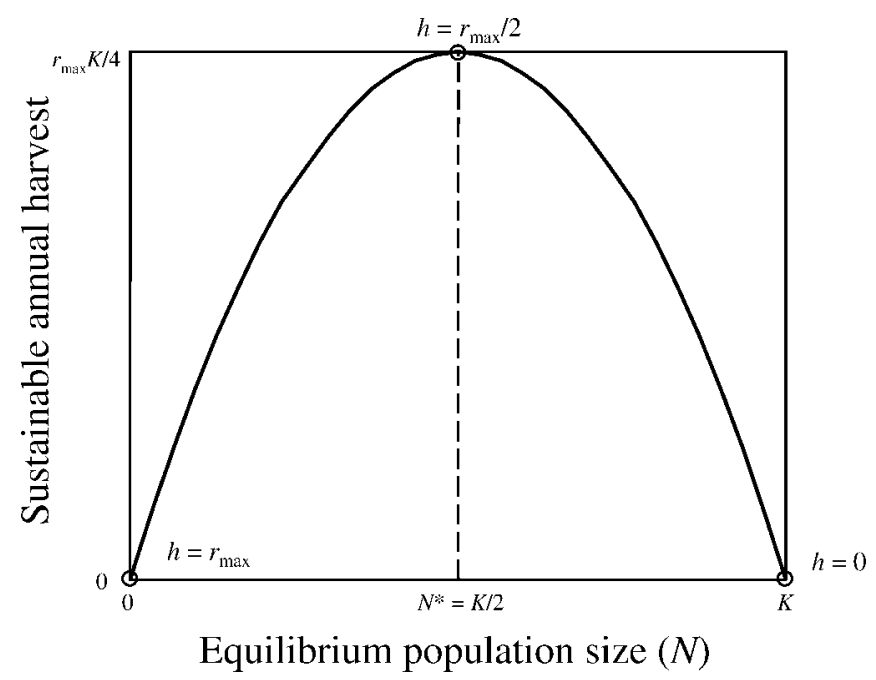

Figure 2. Yield curve for a logistic population model subject to take. We plotted sustainable annual harvest against the corresponding equilibrium population. In the absence of take (harvest rate $h=0$ ), population equilibrium is at carrying capacity $(K)$, and the sustainable take is zero. At maximum sustained yield $\left(h=r_{\max } / 2\right)$, population equilibrium is at $K / 2$ and the sustainable take is $r_{\max } K / 4$. If the harvest rate is greater than or equal to the maximum growth rate ( $b \geq r_{\max }$ ), the population will ultimately decline to zero.

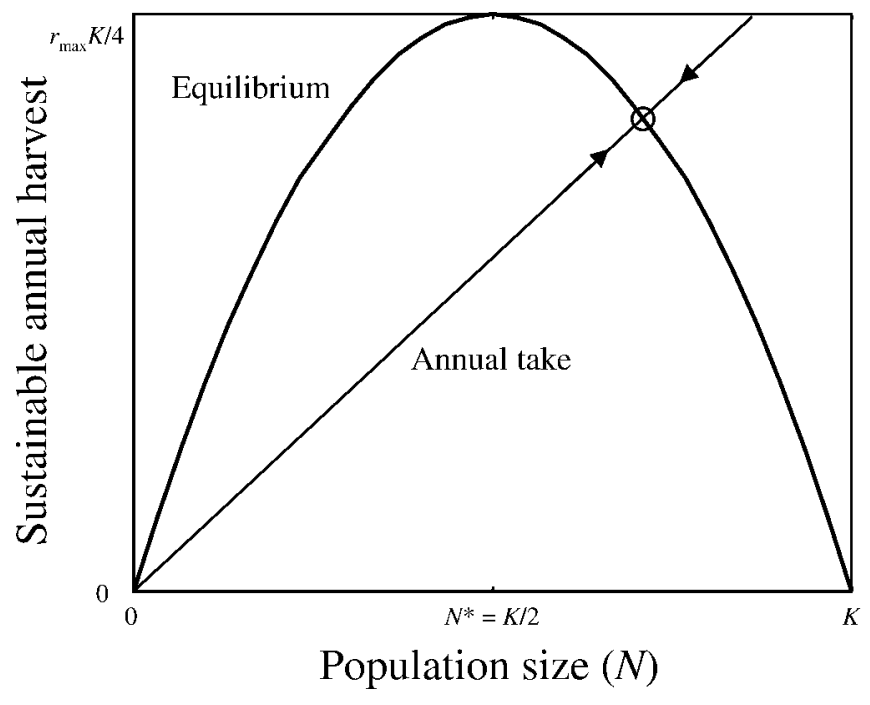

Figure 3. Fixed harvest-rate strategy superimposed on equilibrium yield curve for logistic model. If harvest is less than that which would be sustainable at a particular population, the population will increase. If harvest is greater than sustainable, the population will decrease. Over time, this harvest strategy leads to equilibrium (circle). Any fixed harvest rate between zero and $r_{\max }$ has an associated equilibrium point on the yield curve and can, thus, be viewed as a sustainable strategy.

the time period between $t$ and $t+1$. Under this model, an unharvested population that begins at a small fraction of $K$ will grow quickly at first, then more slowly as it approaches carrying capacity (Fig. 1). A sustained level of take has 2 effects: it slows initial growth of the population and it results in long-term stabilization at a population less than carrying capacity (Fig. 1). At this equilibrium point (where population stabilizes), there is a sustainable annual harvest. The relationship between sustainable annual harvest and equilibrium population (Fig. 2) is known as a yield curve (Caughley 1977, Runge and Johnson 2002, Runge et al. 2006). All points along the yield curve are solutions for sustainable take; a population can be held indefinitely at any population between zero and $K$ by annually removing the corresponding level of take. For the logistic model, this take is maximized (at $r_{\max } K / 4$ ) when the population is held at one-half the carrying capacity $(K / 2)$; the harvest rate at this point is $0.5 \times r_{\max }$ (Caughley 1977, Runge et al. 2004).

A yield curve shows equilibrium points for a harvested population, but a harvest strategy also needs to specify harvest at points away from equilibrium. There is a rich literature on derivation and analysis of harvest strategies (e.g., Quinn and Deriso 1999, Runge and Johnson 2002); among many possible strategies, the fixed harvest-rate strategy is simple and surprisingly robust to uncertainty and stochasticity (Quinn and Deriso 1999). A fixed harvestrate strategy is state-dependent; it adjusts harvest each year based on current population size to maintain a constant harvest rate (Fig. 3). State-dependency allows a harvest-rate strategy to adapt to perturbations and avoid the population vortex that can occur with a fixed harvest-yield strategy. When the population is lower than the equilibrium size associated with a particular harvest rate, the growth rate is 
greater than the harvest rate and the population increases; when the population is higher than the equilibrium population size associated with the harvest rate, the growth rate is less than the harvest rate and the population decreases (Fig. 3).

A particular form of the fixed harvest-rate strategy known as potential biological removal (PBR) has received considerable attention, especially as a means of establishing incidental or allowable take in the face of uncertainty (Wade 1998, Milner-Gulland and Akçakaya 2001, Runge et al. 2004). Potential biological removal was described in the 1994 amendments to the Marine Mammal Protection Act (MMPA) as "the maximum number of animals ... that may be removed from a marine mammal stock while allowing that stock to reach or maintain its optimum sustainable population" (16 USC \$1362) and is calculated as

$$
P B R_{t}=\frac{r_{\max } F_{R}}{2} N_{\min , t}
$$

where $N_{\min }$ is the minimum estimate of the current population size (e.g., min. no. known alive or else a lower bound of a CI; Wade 1998), and $F_{R}$ is a recovery factor between 0.1 and 1.0. Potential biological removal is a fixed harvest-rate strategy, with desired harvest rate set to $r_{\max } F_{R} /$ 2 , and precaution taken in the face of uncertainty by using a minimum estimate, rather than a point estimate, for current population size. Temporal subscripts remind us that take needs to be recalculated each year (or time period). In application under the MMPA, the recovery factor serves as an additional precautionary guard by allowing only a fraction of sustainable harvest to be allocated to take.

The PBR framework can be adapted for use in a broader class of problems to include not only incidental take of depleted species, but also sport harvest and authorized take for management of nuisance wildlife. Changing the terminology to reflect the broader class of problems, let us define prescribed take level (PTL) as

$$
P T L_{t}=F_{O} \frac{\tilde{r}_{\max }}{2} \tilde{N}_{t}
$$

where $F_{O}$ is a factor that reflects management objectives and where tildes $(\sim)$ over $r_{\max }$ and $N_{t}$ indicate that these values are taken from within the uncertainty distributions of these parameters. This version of the formula allows us to delineate the roles of science and policy in setting a level of prescribed (or allowable) take. 1) Estimating $r_{\max }$ and $N_{t}$ is a scientific exercise that should proceed by whatever method is best given available data (see application to black vultures below). Because neither $r_{\max }$ nor $N_{t}$ is typically known with certainty, the most appropriate output from scientific analysis is a distribution for each quantity that reflects uncertainty in its value. 2) The choice of a value from the uncertainty distribution for $r_{\max }$ or $N_{t}$ is a policy decision, because it reflects the risk attitude of the decisionmaker (perhaps as guided by appropriate laws and regulations). For instance, in a setting where a species is rare or declining, the decision-maker might be averse to the risk of local extirpation of the species, in which case choosing values from the lower tails of the uncertainty distributions would be appropriate. In a setting where the greater risk might be losing control of a population that is causing damage, the decision-maker might wish to err on the side of greater harvest and choose values from the upper tails of the uncertainty distributions. 3) The choice of $F_{O}$ reflects the overall goals of the decision-maker and is related to the desired long-term population size relative to the carrying capacity. Any value of $F_{O}$ between zero and 2 (i.e., harvest rate, $h$, between zero and $r_{\max }$; see Fig. 2) produces a sustainable harvest strategy. With $F_{O}$ near zero ( $b$ near zero), little take is allowed and the population is expected to equilibrate near its carrying capacity. With $F_{O}=1\left(b=r_{\max } /\right.$ $2)$, the harvest strategy seeks maximum sustained yield and holds the population at about half the carrying capacity. With $F_{O}$ near 2, the harvest rate is near $r_{\max }$ and the population is held at a small fraction of its carrying capacity. Equilibrium dynamics of the PTL framework can be expressed, in fact, in terms of the objective factor, $F_{O}$. If parameters $r_{\max }$ and $N_{t}$ are known with precision, desired harvest rate is

$$
h=\frac{r_{\max }}{2} F_{O},
$$

equilibrium population as a fraction of carrying capacity is

$$
\frac{N_{e q}}{K}=1-\frac{F_{O}}{2},
$$

and equilibrium annual take $(Y)$ as a fraction of maximum sustainable yield (MSY) is

$$
\frac{Y}{M S Y}=F_{O}\left(2-F_{O}\right) .
$$

In practice, $r_{\max }$ and $N_{t}$ are not known with precision, so equilibrium conditions depend on how the decision-maker chooses values for these parameters given their uncertainty, but we believe that equations 4-6 are nevertheless useful in helping the decision-maker set $F_{O}$.

We offer the PTL framework as a default method for determining allowable take in the face of uncertainty, with flexibility for application over a spectrum of settings. The PTL framework requires estimates of $r_{\max }$ and $N_{t}$ (or only $r_{\max }$ if eq 4 is used to set harvest rate directly) preferably with explicit articulation of uncertainty, and it requires the decision-maker (or regulatory agency) to set an objective $\left(F_{O}\right)$ and to determine how to set take in the face of uncertainty about the parameters. We demonstrate use of this framework for authorized take for nuisance control of black vultures in Virginia.

\section{METHODS}

To provide the scientific components of the framework for take, we estimated the growth rate and population size of black vultures in Virginia. Recognizing that there is limited information about the demography and population dynamics of this species in Virginia, we mined whatever indirect information we could, articulated sources of uncertainty, and explicitly estimated the degree of uncertainty using a variety of methods. 


\section{Demography of Black Vultures}

Black vultures are long-lived birds with delayed onset of breeding, low fecundity, and long-term monogamous pair bonds (Buckley 1999). There has been only one long-term study of black vulture breeding biology (Rabenold and Decker 1990, Decker et al. 1993), and no analysis of survival using modern mark-recapture methods has been undertaken.

There is limited research on survival rates of black vulture adults, juveniles, and subadults. Leg bands cannot be used on black vultures or turkey vultures (Cathartes aura) because their habit of urohidrosis as a cooling mechanism can lead to infection, swelling, and loss of banded legs (Henckel 1976), so alternate methods of estimating survival are used. Because of vultures' long-term pair-bonding, Rabenold and Decker (1990) inferred mortality from single-mate turnovers in established pairs. Based on 12 turnovers at 17 nest sites over 13 years, Rabenold and Decker (1990) estimated adult mortality to be $9.4 \%$ (12 turnovers in 128 pair-yr, exact $95 \%$ binomial $\mathrm{CI}=4.94-15.80 \%)$. The record age for a black vulture is 25 years and 6 months (Clapp et al. 1982, Klimkiewicz 2006). Rabenold (1986) observed 32 out of 41 young black vultures $(78.0 \%)$ surviving $\geq 2$ months after fledging; 2-month survival was $93 \%$ for fledglings with strong parental associations but only $46 \%$ for fledglings with weak parental associations.

There is limited data on survival rates of other vulture species, whether New World or Old World. In perhaps the best study of vulture survival, adult survival of griffon vultures (Gyps fulvus) in a reintroduced population in France was $98.7 \%(95 \% \mathrm{CI}=96.5-99.5 \%)$, and annual survival of young $(<3 \mathrm{yr})$ born in the wild was $85.8 \%(95 \% \mathrm{CI}=76.1-$ 91.9\%; Sarrazin et al. 1994).

Black vultures, like other New and Old World vultures, exhibit delayed onset of sexual maturity. Blackwell et al. (2007) demonstrated via a stage-structured matrix model that age-at-first-breeding must be closer to 5 years than to 8 years (the sole record for a known-age black vulture; Parker et al. 1995). Age-at-first-breeding is typically 4 years in griffon vultures (Blanco and Martinez 1996, Sarrazin et al. 1996) and 4-6 years in Cape vultures (Gyps coprotheres; Robertson 1984).

Periodicity of nesting in New World vultures is not well studied, but there are suggestions that annual nesting may be the norm for established pairs of vultures (Jackson 1983). The proportion of griffon vultures $>4$ years that nested was between $85 \%$ and $99 \%$ in the last 6 years of the study of a reintroduced population (Sarrazin et al. 1996).

Clutch size of black vultures is typically 2 eggs (Jackson 1983). Mean number of eggs that hatch was estimated to be 0.98 per nest, and total nesting success rate (from laying to fledging) was estimated to be $37.6 \%$ (Jackson 1983). In a 13-year study in North Carolina, USA, mean fledglings per nesting attempt averaged 1.29, ranging from 0.68 in new sites to 1.34 in established nest sites (Rabenold and Decker 1990). It is conceivable that fecundity values may be higher now than in the past (when many of these field studies were conducted), as the concentration of dichloro-diphenyltrichloroethane (DDT) metabolites and other persistent organochlorine pesticides, and their reproductive effects, have decreased.

\section{Estimating $r_{\max }$}

We desired an estimate of population growth rate in the absence of take and at low density, under otherwise average environmental conditions. This growth rate is rarely observed, unless through reintroduction, expansion of range, or recovery from a severely depleted status. A direct method of estimation would be to fit equation 1 to a time-series of population size and harvest (e.g., Millar and Meyer 2000). Lacking the appropriate time-series to estimate $r_{\max }$ directly, an alternative is to build a population model based on the life-history of the species, incorporating parameter estimates that reflect demography in the absence of take and at low density. For a delayed breeder like the black vulture, age- or stage-structured matrix approaches are appropriate. Blackwell et al. (2007) used such an approach to find a point estimate for growth rate and perform sensitivity analysis but did not seek specifically to estimate $r_{\max }$ and did not formally incorporate estimates of uncertainty. However, as noted earlier (see also Blackwell et al. 2007), limited species longitudinal data necessitate a degree of speculation in estimating uncertainty.

To estimate $r_{\max }$, we used Slade's formula (Slade et al. 1998, Runge et al. 2004), which requires estimates of ageat-first-breeding $(\alpha)$, age of senescence $(\omega)$, number of offspring per reproductive adult (not per pair) per time period $(b)$, adult survival rate $(p)$, and survival from birth to age-at-first-breeding $\left(l_{\alpha}\right)$; we find growth rate $\left(\lambda=r_{\max }+1\right)$ by solving

$$
1=p \lambda^{-1}+l_{\alpha} b \lambda^{-\alpha}-l_{\alpha} b p^{(\omega-\alpha+1)} \lambda^{-(\omega+1)} .
$$

To account for uncertainty in demographic parameters for black vultures (and specifically, black vultures in VA), we described each parameter with a probability distribution, used Monte Carlo methods to sample from those distributions independently, solved equation 7 numerically for $\lambda$, and used the results from 10,000 replicates to describe uncertainty in $r_{\max }$ (i.e., $\lambda-1$ ).

We assumed that $\alpha$ was between 4 and 6 , based particularly on comparison to Old World vultures, and described uncertainty with a discrete uniform distribution (giving equal probability to an age-at-first-breeding of $4 \mathrm{yr}$, 5 yr, or 6 yr). Similarly, we described uncertainty about $\omega$ with a discrete uniform distribution between 20 years and 30 years, based on observed longevity and assuming that reproductive senescence does not occur until old age, if at all. We used a uniform distribution for adult survival with range $(0.842,0.995)$, taking the low end from the lower confidence interval from Rabenold and Decker (1990) and the high end from the upper confidence interval from Sarrazin et al. (1994). We described number of young per reproductive adult as the product of propensity (uniform between 0.85 and 0.99 ) and fledglings per nesting attempt (uniform between 1.29 and 1.58; mean and upper estimates 
from Rabenold and Decker [1990]), divided by 2 (the 2 parents). We described survival to breeding $\left(l_{\alpha}\right)$ as the product of first-year survival (uniform between 0.7 and 0.9; a wide interval to capture substantial uncertainty) and subadult survival (logit-normal to estimate the interval given by Sarrazin et al. [1994]) raised to the power of $\alpha-1$.

\section{Estimating Population Size from North American Breeding Bird Survey Data}

There is no standardized survey designed specifically to estimate the population of black vultures in Virginia. There are many data sets that represent some ad hoc sampling of black vultures in different ways and at different times of year (e.g., Christmas Bird Count, roost counts), but it is difficult to know how to make inferences from these to the statewide population. The North American Breeding Bird Survey (BBS; Sauer et al. 2007) is the only standardized, randomized survey with a known sampling frame that could be used to estimate vulture population size. There are several problems, however, with using the BBS for this purpose: 1) the BBS is designed to estimate population trends, not population size; 2) the BBS has an incomplete sampling frame, because surveys are only conducted along roads; 3 ) detection probability and availability (birds that could be sampled using the survey method) are not estimated during the BBS; and 4) the sampling radius is vague. Nevertheless, we attempted to estimate black vulture population size in Virginia from BBS data because there was no other option. We used auxiliary data to address deficiencies of the BBS data. In particular, data were available from independent studies to estimate probability of detection of black vultures at BBS stops, on-road-off-road bias, and availability of black vultures for detection.

We assumed that any vulture in flight within the radius of the count was available for detection, and we were able to estimate frequency of flight from satellite telemetry. Some vultures that were perched or on the ground were also available for detection, but we did not have a way to estimate the fraction of these birds that were available. Instead, we used information about the fraction of vultures detected in flight (vs. perched or on the ground) to calculate an estimate of availability from satellite telemetry data.

At Beaufort, South Carolina, USA, during September 2006, we captured black vultures in a baited walk-in trap and attached satellite transmitters (PTT-100 Argos Global Positioning System; Microwave Telemetry, Inc., Columbia, $\mathrm{MD)}$ to 6 birds using a backpack harness of Teflon tape (DuPont, Inc., Wilmington, DE; Humphrey et al. 2000). We programed each transmitter to provide location, altitude, and speed hourly from 0500 hours to 2000 hours. For this analysis, we used data collected during April-June 2007. We adjusted each hourly reading in relation to local sunrise, and for each bird we selected all locations recorded between 0.5 hours before sunrise and 4 hours after sunrise, which is when the BBS is conducted (Robbins et al. 1986). For each record, we determined whether the bird was flying (i.e., speed $>0$ ). We viewed these as binomial trials, with bird as a random effect, and calculated the probability that a bird was flying in this interval of time.

To use the fraction of time spent in flight as an availability adjustment, we needed to use only flying birds in the analysis (Rosenberg and Blancher 2005). However, not all of the vultures detected during the BBS are in flight; flight status of vultures is not regularly recorded during the BBS. To estimate the fraction of vultures detected in flight (vs. perched), we contacted several observers during the 2007 survey and asked them to provide this information. We used observed numbers of birds perched and in flight from these observers to calculate the fraction of BBS observations that were of birds in flight.

We conducted a hierarchical analysis of BBS data in WinBUGS (Lunn et al. 2000) to estimate the black vulture population in Virginia. We used raw observations from the BBS routes in Virginia for the 1966-2006 surveys, stratified into 3 ecoregions. We assumed the radius of sampling for each BBS stop was $400 \mathrm{~m}$ (Rosenberg and Blancher 2005) to calculate density of black vultures, which we multiplied by area of the state to estimate population size. We then corrected this estimate for 3 components. First, we applied a visibility correction factor, based on results of doubleobserver estimation from data collected on and off roads in the northeastern United States using BBS-style counts (Nichols et al. 2000). Second, we converted the result to a count of flying birds only, based on the estimate of the fraction flying. Third, we adjusted the result based on the estimated proportion of time that birds were in flight during the time of day the survey was conducted (availability).

The hierarchical log-linear model used for analysis of BBS data is described in Link and Sauer (2002) and Sauer et al. (2008). In the model, year effects are estimated controlling for observer differences and other nuisance parameters, and annual indices of abundance are constructed from exponentiated year effects and variance components. In the black vulture analysis, we converted these indices to abundance estimates by 1 ) adding the log detection rate to year effects before exponentiation, 2) multiplying the resulting index by the effective area of sampling associated with each route, 3 ) multiplying the resulting population index by the proportion observed to be flying during the survey, and 4) dividing the resulting estimate of flying black vultures by the availability data estimated from radiotracked birds. We captured and propagated through the model uncertainty in the estimates of all these components. We incorporated detectability as log-normally distributed variables with estimated detection rates forming means and variances; we incorporated the proportion flying and availability data as beta distributions with means and variances formed by field-based estimates.

\section{RESULTS}

The median estimate of $r_{\max }$ was $10.58 \%$, with the central $95 \%$ of the uncertainty distribution contained in the interval $[2.06 \%, 19.23 \%]$ and the central $60 \%$ contained in the interval $[6.86 \%, 14.33 \%]$ (Fig. 4). Uncertainty in the 


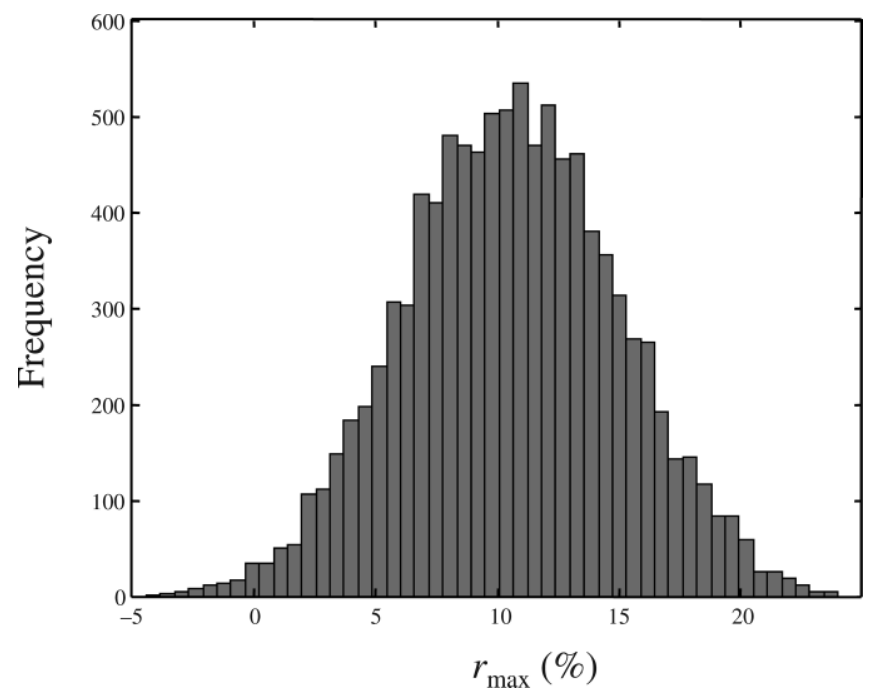

Figure 4. Maximum growth rate $\left(r_{\max }\right)$ for black vultures, based on their life-history and parameter estimates from the literature, calculated using the formula of Slade et al. (1998). We captured uncertainty by sampling from distributions that represented uncertainty in the underlying life-history parameters and propagating this uncertainty through the population model ( $n=10,000$ replicates). Median of the distribution shown was $10.58 \%$; the central $60 \%$ of the distribution was in the interval $[6.86 \%, 14.33 \%$ ].

estimate of $r_{\max }$ was driven most strongly by uncertainty in age-at-first-breeding, adult survival rate, and subadult survival rate (Fig. 5).

We assumed that birds in flight were available for
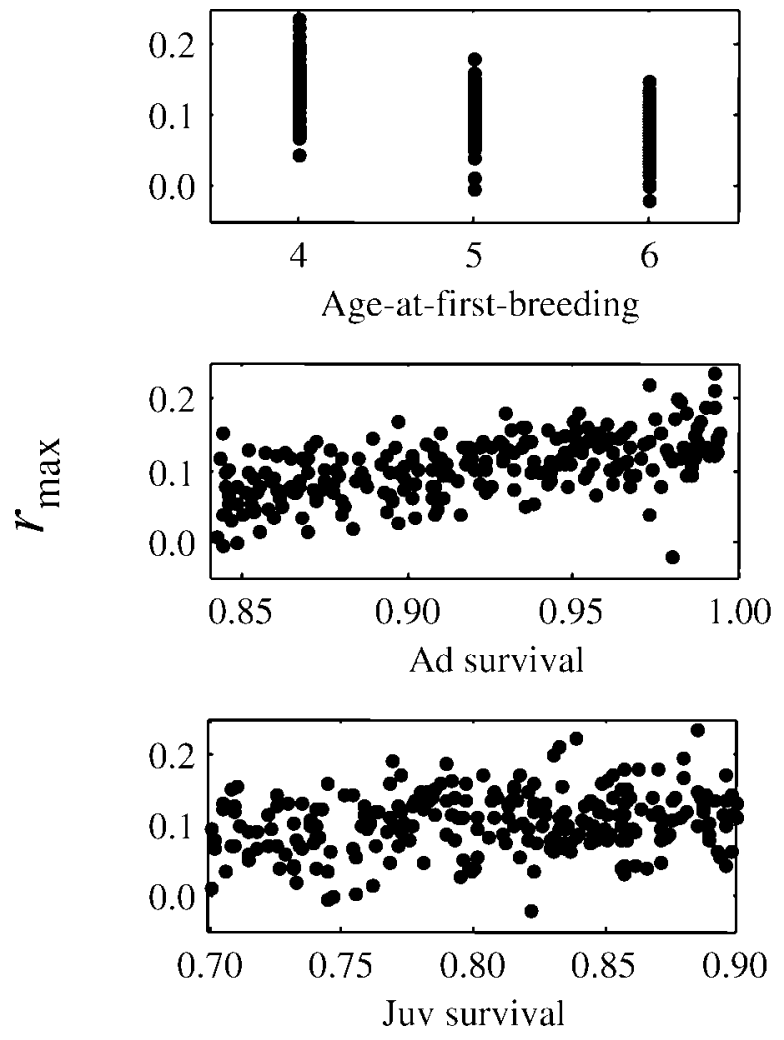

Table 1. Fraction of time flying for 6 black vultures equipped with Global Positioning System (GPS) satellite transmitters, 0.5 hours before to 4.0 hours after sunrise, April-June 2007, Beaufort, South Carolina, USA. We determined birds to be flying, and hence available for detection, if their speed was $>0$.

\begin{tabular}{cccc}
\hline Bird identification no. & $\begin{array}{c}\text { No. GPS } \\
\text { locations }\end{array}$ & No. flying & Availability \\
\hline BLVU47 & 358 & 15 & 0.042 \\
BLVU48 & 275 & 21 & 0.076 \\
BLVU49 & 269 & 8 & 0.030 \\
BLVU50 & 211 & 11 & 0.052 \\
BLVU57 & 258 & 7 & 0.027 \\
BLVU58 & 305 & 7 & 0.023 \\
\hline
\end{tabular}

detection. During April-June 2007, between 0.5 hours before sunrise and 4 hours after sunrise, the 6 satellitetagged black vultures were flying between $2.3 \%$ and $7.6 \%$ of the time (Table 1). The mean fraction of time flying was $4.17 \%(95 \%$ Bayesian credible interval $=2.13-6.85 \%)$. Because we based our availability correction on the fraction of time flying, we needed to adjust BBS counts to reflect detections of flying vultures only. In June 2007, 5 observers in central Maryland, USA, recorded 86 vultures (both species), of which 37 were in flight, on 6 BBS routes. Mean estimate for percent of birds in flight was $43.0 \%$ (95\% Bayesian credible interval $=32.7-53.6 \%$ ).

In 2006, the median black vulture population estimate in Virginia was 91,190 (95\% credible interval $=44,520$
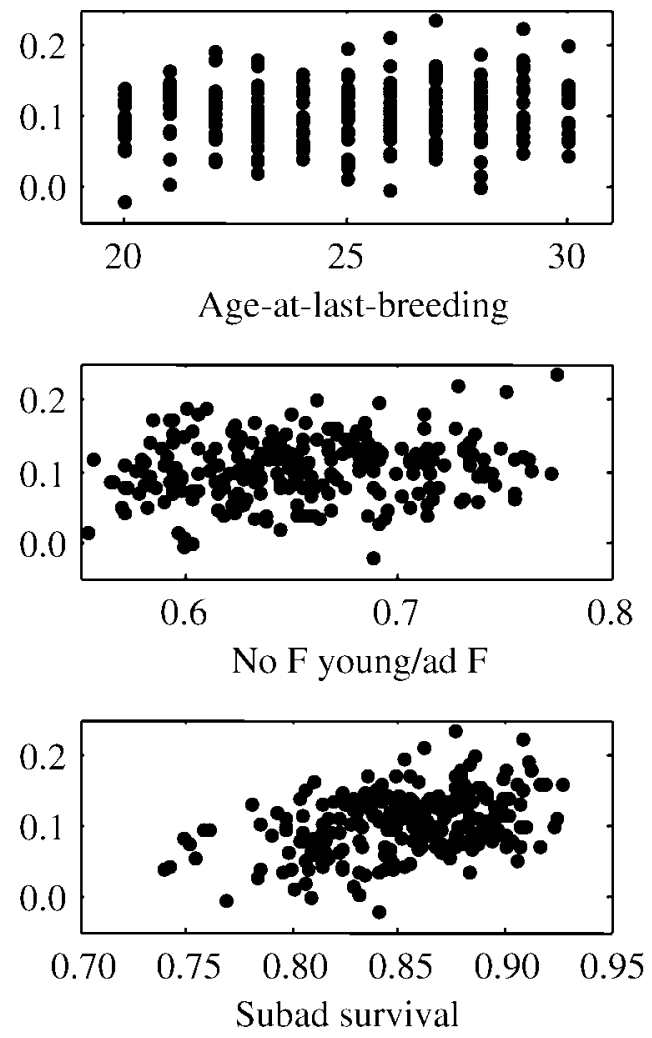

Figure 5. Sensitivity analysis of the maximum growth rate $\left(r_{\max }\right)$ for black vultures, based on their life-history and parameter estimates from the literature, with maximum growth rate calculated using the formula of Slade et al. (1998). On each graph, we plotted $r_{\max }$ against one of the underlying life-history parameters for 250 of the 10,000 replicates. Uncertainty in age-at-first-breeding, adult survival, and subadult survival most strongly influence uncertainty in $r_{\text {max }}$, as evidenced by the steep slopes. 


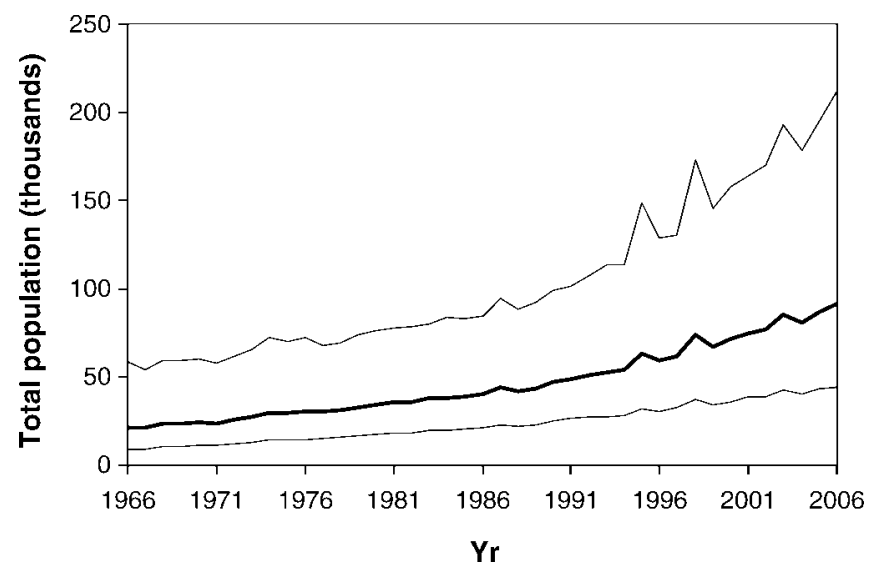

Figure 6. Population size of black vultures in Virginia, USA, 1966-2006. We show median and $95 \%$ credible intervals from the posterior distributions. We based these estimates on Breeding Bird Survey trends and incorporated correction factors for detectability, availability, and area sampled.

212,100; Fig. 6). Our estimates of black vulture population in Virginia from 1996 to 2006 (Fig. 6) incorporate detection probability (which we estimated as 0.95 based on limited data, and no differences existed on- vs. off-road), availability (including the fraction of BBS vulture observations in flight), and an area-correction. The lower end of the $60 \%$ credible interval was 66,660 .

\section{DISCUSSION}

Our results provide several important advances for understanding black vulture demography and take, with implications for other species of migratory birds. First, we were able to estimate the intrinsic rate of growth for black vulture populations, even with very sparse data, by explicitly incorporating uncertainty. Second, we were able to estimate the statewide population of black vultures from BBS data and auxiliary information, providing a critical population parameter to managers. Third, the PTL framework provides a context for integrating the scientific and policy elements of take management for migratory birds.

\section{Scientific Considerations}

Estimating $r_{\max }$ for black vultures is challenging because there are no data to estimate $r_{\max }$ directly and the lifehistory data to estimate it indirectly are sparse. In our approach, we articulated wide bounds to describe our uncertainty about each life-history parameter, basing these bounds on published values for black vultures, turkey vultures, and Old World vultures, and propagated that uncertainty through to estimates of $r_{\max }$. We believe that these ranges do, in fact, bound the possible values for the parameters, and thus our distribution for $r_{\max }$ (Fig. 4) bounds the possible values for this growth rate, although we suspect we overstated uncertainty at the low ends of the parameter estimates. We note that the matrix model developed by Blackwell et al. (2007), and based on the same data sources, produced an estimate of population growth for the North Carolina black vulture population of
$10.6 \%$ annually (and also demonstrated the marked sensitivity of this growth rate to the estimate of ad survival rate). Our belief, therefore, is that the median estimate for $r_{\max }(10.6 \%)$ is the best to work with at this time, although it is likely conservative.

Conversion of BBS indices to population estimates is controversial (Rosenberg and Blancher 2005). Many of the conversion factors are not supported by credible data; collection of auxiliary information in the field to facilitate these conversions should be a priority research activity. The most important, and least well known, conversion factor is the availability bias: the proportion of birds available to be detected during the morning hours when the BBS is conducted. In this work, we have equated availability of black vultures with flying and have used data from satellitetagged birds in South Carolina to estimate the fraction of time spent flying. Additional data from other locations would improve these estimates; alternative methods might be used for other species. The estimate of the fraction of black vultures observed in flight during the BBS is from a small and informal sample. There may be value in seeking a formal estimate of this fraction by asking BBS observers to record, as a part of operational procedures, whether vultures and other diurnal raptors are perched or in flight.

The desired spatial scale of assessment and management has a bearing on estimation procedures, particularly because black vulture populations can be influenced by emigration and immigration. The PTL framework implicitly assumes that the population being managed is closed to emigration and immigration, and the framework will work best when the spatial extent of application is large enough that the contribution of emigration and immigration to population growth is minimal. An otherwise sustainable take, applied to a population that is experiencing substantial emigration, could result is an unintended reduction in population. Conversely, an otherwise aggressive take, applied to a population that is experiencing substantial immigration, could fail to control a nuisance problem. The degree of population movement in black vultures is not known, but the observed annual population growth for 1990-2006 based on the BBS was $4.5 \%$ across the United States and $4.8 \%$ in Virginia (Sauer et al. 2007), suggesting that there may not have been net immigration of black vultures to Virginia during that period.

Even if there is minimal movement of birds, there are still some spatial considerations in application of this framework. In vulture damage management, one goal might be substantial reduction, even extirpation, of a vulture population at a local scale (i.e., that of a landowner's property). If the PTL framework were applied at such a scale, it would prevent the specific objective of local damage reduction. The question is, at what scale does take need to be sustainablecountywide, statewide, region-wide, nationwide? At whatever scale it is applied, the conservation assurances of the framework hold over broader ranges but not necessarily more local ones; that is, if take is managed using this framework at the statewide level, then take at the regional 
level will also be sustainable and no larger than specified by the policy parameters, but take at the local level may not. We believe that this decision, although it could be informed to some extent by an understanding of the species' biology, is primarily a policy consideration.

The PTL framework also implicitly assumes that carrying capacity is not changing, but what if it is? For black vultures in Virginia, and elsewhere, their long-term increasing population trend is likely driven in part by increases in key resources, such as roost sites (Avery et al. 2002) and food (i.e., carrion; see Coleman and Fraser 1987, 1989; DeVault et al. 2004). Fortunately, the PTL framework is robust to changes in carrying capacity. For example, consider a population that is harvested at $r_{\max } / 2$ and is, thus, headed toward equilibrium around $K / 2$. If $K$ doubles over a 15 -year period, then the equilibrium point will double as well, and the population size should slowly increase toward that new equilibrium. As long as the management goal is to hold the population near a particular fraction of $K$, rather than a particular absolute population, the PTL framework will work in the face of changing $K$. There is a more insidious problem, however, if the intrinsic growth rate changes, particularly if it decreases and take is not adjusted accordingly, because the population will decline more than intended. Conservatism in the face of uncertainty, and adaptive management, help guard against this risk.

The deterministic discrete logistic model is an oversimplification of the dynamics of any population, in that it leaves out stochastic fluctuations, nonlinear density-dependence, and stage-structure, among other nuances. To the extent any of these dynamics can be quantified, they should be, and allowable take should be assessed with a more detailed model. But we submit that this framework is a robust default framework to use in the absence of better information, and further, this framework allows certain policy questions to be addressed that need to be answered no matter what population model is used.

\section{Policy Considerations}

The PTL framework requires 3 primary policy specifications: the spatial scale of management (discussed above), the desired allocation of growth to take (as expressed by $F_{O}$ ), and the response to uncertainty. We propose some ways to link biological guideposts to policy thresholds, but it is important to note that these proposals are meant to stimulate discussion and should not be construed to represent any determination or policy of our respective agencies.

Setting $F_{O}$ is an important expression of management objectives. As discussed above, there are 3 values of $F_{O}$ that are biological guideposts- 0,1 , and 2 . Take is sustainable if $0 \leq F_{O}<2$, and equilibrium population size is expected to be greater than that at MSY if $F_{O}<1$. In a sense, if $F_{O}<1$, a conservation stance is taken, in that the framework guards against allocating too much productivity to take. But, we can imagine that in some serious nuisance control settings, the management goal may be to reduce the population below $K / 2$ without extirpating it, in which case setting $1<F_{O}<2$ to determine take would be appropriate. It is important to note that the risks (of overharvest and extirpation) due to uncertainty increase greatly as $F_{O}$ approaches 2 .

Can these biological guideposts be tied to policy thresholds under laws that play a role in regulating take in the United States? It would be advantageous if they could, because it would allow decision-makers to articulate their policy thresholds in an explicit, transparent, and replicable manner. However, we recognize the laws may have more complex interpretations than available biological guideposts allow. Nevertheless, in the spirit of engendering discussion and encouraging management agencies to be explicit about their policy thresholds, we propose the following links between these biological guideposts and several relevant policy thresholds, and we apply them in the context of black vulture management.

The MBTA prohibits take of migratory birds except as authorized by the Secretary of Interior; regulations promulgated by USFWS and upheld in court challenges support the legality of take of native migratory birds for several purposes, provided populations are not imperiled in the process. The range of take approved under the MBTA includes several examples where the desired harvest level was $>0.5 \times r_{\max }$ (e.g., snow geese [Chen caerulescens]; USFWS 2007). Thus, we propose that the MBTA requires only that take of native migratory birds be sustainable, which suggests $0 \leq F_{O}<2$.

The National Environmental Policy Act (NEPA; 42 USC $\S \S 4321-4375)$ is a procedural law that requires, among other things, Federal agencies to clearly articulate the expected environmental consequences of their actions. In particular, NEPA requires an environmental impact statement (EIS) for any "major Federal action significantly affecting the quality of the human environment" (42 USC §4332). For actions with less impact, an Environmental Assessment (EA) may be all that is required, or indeed, a "categorical exclusion" can be granted, meaning neither an EIS nor an EA is required (40 CFR 1508.4). The considerations that go into determination of significance under NEPA are complex and include economic, social, and political, as well as biological impacts. We suggest that $F_{O}$ may be a useful way to summarize biological impacts, but there are no obvious biological guideposts to link to these policy thresholds.

Another policy component to the decision is how to handle uncertainty and risk. The proposed framework requires scientific assessment of the intrinsic growth rate of the population $\left(r_{\max }\right)$ and the population size $(N)$ for the appropriate spatial unit, with appropriate expression of the uncertainty in those estimates, preferably as a probability distribution. The choice of a particular value for each of these parameters from the range that captures uncertainty about them is a decision that articulates the risk tolerance of the decision-maker. Choosing low values for these parameters (e.g., taking the lower CLs) provides assurance that the population will remain above the level prescribed by the management objective, $F_{O}$ (see eq 5 ), but being unnecessar- 
ily conservative can undermine the ability to accomplish the overarching management goals (e.g., nuisance control, hunter satisfaction). Wade (1998) found that using the lower end of a $60 \%$ confidence interval for $N$ (i.e., the 20 th percentile), while using the best estimate for $r_{\max }$, provided sufficient protection against the types of uncertainty typical in application of PBR to marine mammals. Further work is needed to determine whether this recommendation holds for a broader set of contexts, but we believe this recommendation is a good starting point for consideration. It should be adjusted, however, by consideration of the risk tolerance for a specific context and perhaps also adapted as experience provides feedback (see below). Note that it is possible to perform a formal risk analysis and look at how the choice of specific points in the uncertainty distributions for the 2 parameters affects long-term outcomes (e.g., expected population size, risk of dropping below a specific population size). This risk analysis requires a more detailed population model (e.g., estimates of stochastic variance, expression of structural and parametric uncertainty) but can and should be performed when the consequences of management require a more detailed understanding of risk.

\section{Adaptive Management of Take}

Take can often be managed adaptively. In many cases, the decision to authorize take is revisited periodically, and there are monitoring data generated in between, which can provide feedback about effects of the take. Monitoring can guard against effects of, and can reduce, uncertainty if management actions can be adjusted based on new information. This requires, first, that take levels be set in a state-dependent manner, that is, based on annual updates of $N$, and perhaps other parameters. As new information is acquired about $r_{\max }$ and $N$, either from direct observation of the population being managed or from auxiliary studies, the parameters used to calculate allowable take should be updated.

Adaptive management is often applied to resolve uncertainty about parameters that are part of the scientific assessment, but there has been increased attention in recent years to double-loop learning (Lee 1993) in which resolution of uncertainty about policy parameters is also given attention, albeit at a less frequent rate. In the case of allowable take, periodic review of the objectives (as expressed by $F_{O}$ ) and risk tolerance is appropriate and necessary.

\section{Allowable Take of Black Vultures in Virginia}

Together, the analytical results and the policy proposals we discussed suggest the following assessment for allowable take of black vultures in Virginia. We assume that the appropriate spatial scale for management is the state of Virginia, but USFWS would have to determine, as a matter of policy, whether that is the appropriate scale at which to pursue sustainability and manage take. Using the median estimate for $r_{\max }(10.6 \%)$ and the 20th percentile for the population size in $2006(66,660)$, we calculate allowable take at 3,533 (for $F_{O}=1$ ) or 7,066 (for $F_{O}=2$ ). In applying for a take permit, the applicant would specify the management objective in terms of how much growth should be allocated to take $\left(F_{O}\right)$. Take governed by $F_{O}$ between zero and 2 (take in 2006 between zero and 7,066) could possibly be authorized. Take $<3,533 /$ year contains some assurance that the long-term population size in Virginia will remain $>K / 2$, but if the desire is to take $>3,533$ year $\left(F_{O}>1\right)$, the responsible agency might need to further analyze take to determine its significance. Specification of a management objective $\left(F_{O}\right)$ and advance determination of how uncertainty is to be handled (e.g., using the median estimate for $r_{\max }$ and the 20th percentile of $N$ ), would help the agency make clear to the public how annual allowable take would be recalculated based on updated estimates of $r_{\max }$ and $N_{t}$. Periodically, with renewal of the planning document, the policy parameters (as expressions of the management objectives) could be revisited.

\section{MANAGEMENT IMPLICATIONS}

Regulatory decisions about take of migratory birds, in North America and elsewhere, have not always been made under a comprehensive and consistent approach grounded in harvest theory, especially outside of the context of sport harvest. The PTL approach provides a decision-analytic framework for assessing and setting allowable take of migratory birds and other animals. The framework is applicable to a broad set of problems, including take associated with nuisance control, sport harvest, falconry (Millsap and Allen 2006), and incidental take. The framework requires that management goals be explicit and transparent, provides a clear delineation of the roles of policy and science, and can be implemented adaptively. We believe this framework can improve communication and coordination among regulatory agencies and with affected constituencies, as it has in the case of black vultures.

\section{ACKNOWLEDGMENTS}

We are grateful to G. Allen, R. Chipman, C. Dwyer, K. Fagerstone, P. Garrettson, M. Linnell, G. Littauer, M. Lowney, J. Lyons, J. Nichols, K. Pardieck, D. Pence, B. Peterjohn, B. and A. Rattner, D. Reinhold, C. Robbins, F. Rivera, M. Seamans, and M. Tobin for insights in the development of this paper. M. Chamberlain, D. Euler, and 2 anonymous reviewers offered helpful suggestions that improved the paper. Conclusions contained in this paper are presented for heuristic value and do not necessarily reflect policy of any agency.

\section{LITERATURE CITED}

Avery, M. L. 2004. Trends in North American vulture populations. Proceedings of the Vertebrate Pest Conference 21:116-121.

Avery, M. L., J. S. Humphrey, E. A. Tillman, K. O. Phares, and J. E. Hatcher. 2002. Dispersal of vulture roosts from communication towers. Journal of Raptor Research 36:44-49.

Blackwell, B. F., M. L. Avery, B. D. Watts, and M. S. Lowney. 2007. Demographics of black vultures in North Carolina. Journal of Wildlife Management 71:1976-1979.

Blanco, G., and F. Martinez. 1996. Sex differences in breeding age of griffon vultures (Gyps fulvus). Auk 113:247-248. 
Buckley, N. J. 1999. Black vulture (Coragyps atratus). Account 411 in A. Pool and F. Gill, editors. The birds of North America. The Academy of Natural Sciences, Philadelphia, Pennsylvania, and The American Ornithologists' Union, Washington, D.C., USA.

Caughley, G. 1977. Analysis of vertebrate populations. John Wiley and Sons, New York, New York, USA.

Clapp, R. B., K. Klimkiewicz, and J. H. Kennard. 1982. Longevity records of North American birds: Gaviidae through Alicidae. Journal of Field Ornithology 53:81-124.

Coleman, J. S., and J. D. Fraser. 1987. Food habits of black and turkey vultures in Pennsylvania and Maryland. Journal of Wildlife Management 51:733-739.

Coleman, J. S., and J. D. Fraser. 1989. Habitat use and home ranges of black and turkey vultures. Journal of Wildlife Management 53:782-792.

Decker, M. D., P. G. Parker, D. J. Minchella, and K. N. Rabenold. 1993. Monogamy in black vultures: genetic evidence from DNA fingerprinting. Behavioral Ecology 4:29-35.

DeVault, T. L., B. D. Reinhart, I. L. Brisbin, Jr., and O. E. Rhodes, Jr. 2004. Home ranges of sympatric black and turkey vultures in South Carolina. Condor 106:706-711.

Geist, V., S. P. Mahoney, and J. F. Organ. 2001. Why hunting has defined the North American model of wildlife conservation. Transactions of the North American Wildlife and Natural Resources Conference 66:175185.

Greider, M., and E. S. Wagner. 1960. Black vulture extends breeding range northward. Wilson Bulletin 72:291.

Henckel, E. 1976. Turkey vulture banding problem. North American Bird Bander 1:126.

Humphrey, J. S., M. L. Avery, and A. P. McGrane. 2000. Evaluating relocation as a vulture management tool in North Florida. Proceedings of the Vertebrate Pest Conference 19:49-53.

Jackson, J. A. 1983. Nesting phenology, nest site selection, and reproductive success of black and turkey vultures. Pages 245-270 in S. R. Wilbur and J. A. Jackson, editors. Vulture biology and management. University of California Press, Berkeley, USA.

Klimkiewicz, M. K. 2006. Longevity records of North American birds. Version 2006.1. Patuxent Wildlife Research Center Bird Banding Laboratory, Laurel, Maryland, USA. <http://www.pwrc.usgs.gov/bbl/ homepage/longvrec.htm>. Accessed 24 Jan 2007.

Lee, K. N. 1993. Compass and gyroscope: integrating science and politics for the environment. Island Press, Washington, D.C., USA.

Link, W. A., and J. R. Sauer. 2002. A hierarchical model of population change with application to cerulean warblers. Ecology 83:2832-2840.

Lowney, M. S. 1999. Damage by black and turkey vultures in Virginia, 1990-1996. Wildlife Society Bulletin 27:715-719.

Lunn, D. J., A. Thomas, N. Best, and D. Spiegelhalter. 2000. WinBUGS-a Bayesian modelling framework: concepts, structure, and extensibility. Statistics and Computing 10:325-337.

Millar, R. B., and R. Meyer. 2000. Non-linear state space modelling of fisheries biomass dynamics by using Metropolis-Hastings within-Gibbs sampling. Applied Statistics 49:327-342.

Millsap, B. A., and G. T. Allen. 2006. Effects of falconry harvest on wild raptor populations in the United States: theoretical considerations and management recommendations. Wildlife Society Bulletin 34:1392-1400.

Milner-Gulland, E. J., and H. R. Akçakaya. 2001. Sustainability indices for exploited populations. Trends in Ecology \& Evolution 16:686-692.

Nichols, J. D., J. E. Hines, J. R. Sauer, F. W. Fallon, J. E. Fallon, and P. J. Heglund. 2000. A double-observer approach for estimating detection probability and abundance from points counts. Auk 117:393-408.

Parker, P. G., T. A. Waite, and M. D. Decker. 1995. Kinship and association in communally roosting black vultures. Animal Behavior 49: 395-401.
Quinn, T. J., II, and R. B. Deriso. 1999. Quantitative fish dynamics. Oxford University Press, New York, New York, USA.

Rabenold, P. P. 1986. Family associations in communally roosting black vultures. Auk 103:32-41.

Rabenold, P. P., and M. D. Decker. 1990. Black vultures in North Carolina: statewide population surveys and analysis of Chatham County population trends. Final report to North Carolina Wildlife Resources Commission, Nongame and Endangered Wildlife Program, Contract no. 1989SG07. Purdue University, West Lafayette, Indiana, USA.

Robbins, C. S., D. Bystrak, and P. H. Geissler. 1986. The Breeding Bird Survey: its first fifteen years, 1965-1979. U.S. Fish and Wildlife Service Resource Publication 157, Washington, D.C., USA.

Robertson, A. S. 1984. Aspects of the population dynamics of cape vultures in the Cape Province. Ostrich 55:196-206.

Rosenberg, K. V., and P. J. Blancher. 2005. Setting numerical population objectives for priority landbird species. Pages 57-67 in C. J. Ralph and T. D. Rich, editors. Proceedings of the Third International Partners in Flight Conference. U.S. Department of Agriculture Forest Service General Technical Report PSW-GTR-191, Albany, California, USA.

Runge, M. C., and F. A. Johnson. 2002. The importance of functional form in optimal control solutions of problems in population dynamics. Ecology 83:1357-1371

Runge, M. C., F. A. Johnson, M. G. Anderson, M. D. Koneff, E. T. Reed, and S. E. Mott. 2006. The need for coherence between waterfowl harvest and habitat management. Wildlife Society Bulletin 34:1231-1237.

Runge, M. C., W. L. Kendall, and J. D. Nichols. 2004. Exploitation. Pages 303-328 in W. J. Sutherland, I. Newton, and R. E. Green, editors. Bird ecology and conservation: a handbook of techniques. Oxford University Press, Oxford, United Kingdom.

Sarrazin, F., C. Bagnolini, J. L. Pinna, and E. Danchin. 1996. Breeding biology during establishment of a reintroduced griffon vulture Gyps fulvus population. Ibis 138:315-325.

Sarrazin, F., C. Bagnolini, J. L. Pinna, E. Danchin, and J. Clobert. 1994. High survival estimates of griffon vultures (Gyps fulvus fulvus) in a reintroduced population. Auk 111:853-862.

Sauer, J. R., J. E. Hines, and J. Fallon. 2007. The North American Breeding Bird Survey, results and analyses 1966-2006. Version 10.13.2007. U.S. Geological Survey Patuxent Wildlife Research Center, Laurel, Maryland, USA. <http://www.mbr-pwrc.usgs.gov/bbs/bbs.html>. Accessed 16 Jan 2008.

Sauer, J. R., W. A. Link, W. L. Kendall, J. R. Kelley, Jr., and D. K. Niven. 2008. A hierarchical model for estimating change in American woodcock populations. Journal of Wildlife Management 72:204-214.

Slade, N. A., R. Gomulkiewicz, and H. M. Alexander. 1998. Alternatives to Robinson and Redford's method of assessing overharvest from incomplete demographic data. Conservation Biology 12:148-155.

Tillman, E. A., J. S. Humphrey, and M. L. Avery. 2002. Use of effigies and decoys to reduce vulture damage to property and agriculture. Proceedings of the Vertebrate Pest Conference 20:123-128.

United States Department of Agriculture. 2002. Environmental assessment for the management of vulture damage in the Commonwealth of Virginia. U.S. Department of Agriculture, Animal and Plant Health Inspection Service, Wildlife Services, Moseley, Virginia, USA.

United States Fish and Wildlife Service [USFWS]. 2007. Final Environmental Impact Statement: light goose management. U.S. Department of Interior, Fish and Wildlife Service, Washington, D.C., USA.

Wade, P. R. 1998. Calculating limits to the allowable human-caused mortality of cetaceans and pinnipeds. Marine Mammal Science 14:1-37.

Associate Editor: Euler. 